\title{
Misticismo laico en los tiempos de la contracultura: Edward Stachura y Julio Cortázar
}

\section{Resumen:}

Al cotejar la narrativa de dos autores que afianzaron su renombre en los años 60 del siglo XX, el argentino Julio Cortázar y el polaco Edward Stachura, resulta significativo que los protagonistas ficticios de ambos comparten el anhelo de alcanzar un ámbito de una vida más auténtica que el que ofrecían las sociedades burguesas occidentales de la posguerra. Continuando, por un lado, las inspiraciones de las primeras vanguardias y sensibles, por otro lado, a los nuevos aires contestatarios - que desembocarían en las revoluciones contraculturales entre los años 60 y 70 del s. XX - los autores postulan una serie de espacios simbólicos y trascendentes (p. ej. el kibbutz del deseo en Rayuela de Cortázar), donde el hombre se vería libre de la sumisión impuesta por el capitalismo y la moral burguesa.

Palabras claves: Julio Cortázar, Edward Stachura, narrativa del siglo XX, contracultura, ficción existencialista

\section{Abstract: \\ Lay Mysticism in the Counetrculture Era: Edward Stachura and Julio Cortázar \\ When checking the psychology of the protagonists in the fiction of two writers from the same period of the sixties and seventies of the $20^{\text {th }}$ century - the Polish writer Edward Stachura and the Argentinian Julio Cortázar, it comes out that they both writers share the eagerness to reach a transcendental sphere of happiness,}


where life is more authentic than by the middle class standards. They are both inspired by the first Avant-Garde movements, as well as by the countercultural tendencies of their times. Their protagonists dream about symbolical places - like the kibbutz of desire in Cortázar's Hospscotch - where the man could eventually feel free from middle class morals and submission imposed by the capitalist system.

Keywords: Julio Cortázar, Edward Stachura, 20th century fiction, counterculture, existentialist fiction

“La vida está más allá”, Sorbona, mayo 1968.

Al poner en contacto la narrativa de dos escritores cuyo renombre se afianza en los años 60. del s. XX, el argentino Julio Cortázar y el polaco Edward Stachura, se advierte una especie de misticismo laico común en las posturas de sus protagonistas. Aunque proceden de dos extremos opuestos del ámbito de la cultura occidental (Hispanoamérica, Europa Centrooriental), en la prosa de ambos, sobre todo aquella de los años sesenta y de la década siguiente, se perciben unas aspiraciones parecidas, concordes con las tendencias contraculturales que se iban haciendo patentes en las sociedades de la posguerra.

Entre los años 60 y 70 ambos escritores eran ya reconocidos por la crítica y por nutridas filas de lectores en sus respectivos países, incluso, en el caso de Cortázar, en el ámbito internacional. El argentino había ido publicando, desde 1951, sus volúmenes de relatos en los que exploraba la modalidad neofantástica, así como sus novelas más importantes, entre ellas, la más aclamada, Rayuela (1963), y otras, 62/Modelo para armar (1969) y Libro de Manuel (1973)1. A su vez, Edward Stachura, después de sus comienzos a principios de los 60 (como poeta y autor de un volumen de relatos), se consagra con la publicación de su novela Cata jaskrawość ([Todo resplandor], 1969). Fue atrayendo a los lectores con un nuevo tipo de personaje, vagabundo,

${ }^{1}$ En esta última había quedado clara su voluntad de reforzar la siempre discutida relación entre literatura y política. 
idealista y rebelde, y ganándose el aprecio de la crítica gracias a una narración original, en la que se refundía líricamente "la doble voz del relato coloquial de un vagabundeo, en el que se sufre hambre y desamparo, y de un lirismo de sublime plegaria" (Mach cit. por Pachocki 2007: 141). De forma categórica un periodista especializado en música pop diría: „Stachura era la respuesta polaca a toda la agitación en la cultura mundial de mediados del siglo XX: A Cortázar, a los experimentos de los beatniks, a la contracultura." (Sankowski: 2012, trad. mía).

¿Se conocían el uno al otro? Stachura debió haber leído la obra del argentino, ya que la temprana traducción de Rayuela en Polonia, en 1969, había causado gran revuelo en el mundo literario (GaszyńskaMagiera, 2011: 119-121). A principios de los 70. Stachura tenía dominio del español, ya había estado con una beca en México; tenía asimismo traducidos fragmentos del volumen Último round de Cortázar (y textos de otros autores como Borges). En cambio, es poco probable que Cortázar conociera algo de la obra del escritor polaco.

Aunque Cortázar y Stachura habían sido condicionados por tradiciones literarias y circunstancias político-sociales diferentes, la obra de uno y de otro se puede clasificar dentro de la corriente de la prosa de posguerra en la que se vislumbra la preocupación por lo existencial y la obsesión por la metafísica (que Shaw atribuye, a entre los rioplatenses, a Macedonio Fernández, Bioy Casares, Mallea, Arlt, Borges, así como al mismo Cortázar; Shaw, 2005: 100) ${ }^{2}$. En dicha narrativa late una intensa nostalgia por una vida, llamémosla así, auténtica, exenta de hipocresía y violencia, que entronca con las aspiraciones de los movimientos contraculturales de las décadas de los 70 y 80 .

Los protagonistas se mueven en medios sociales diferentes (grandes urbes en Cortázar, el campo y la provincia polaca en Stachura), sin embargo comparten unas experiencias fronterizas y les caracteriza el

${ }^{2}$ A Cortázar lo sitúa Donald Shaw en una línea de la literatura rioplatense que arranca con Borges y Cortázar, preocupada por la condición humana y acechada por las dudas existenciales. A su vez, en Stachura se pone de relieve sobre todo el esfuerzo del sujeto por transformar su existencia: alejar el sufrimiento síquico y encontrar la motivación suficiente para seguir viviendo (ver. Brach-Czaina: 1984). 
deseo de ir más allá de una realidad rutinaria. Esta aspiración se manifiesta en un gran número de actos extravagantes e ideas subversivas.

Los de Cortázar buscan activamente producir una ruptura con la realidad y llegar hacia una dimensión diferente, en la que el individuo gozaría de una existencia plena. Algunos consiguen efectuar una especie de "ritos de paso", cuando la revelación (a veces casual) de lo insólito los sitúa en una posición totalmente nueva en el mundo, aboliendo coordenadas, relaciones y valores (Elbanowski, 1983: 124-126). Vislumbran entonces unos espacios donde, al decir de Oliveira, el protagonista de Rayuela, no es hombre, sino que ,busca ser, proyecta ser manoteando entre palabras y conducta y alegría salpicada de sangre" (Cortázar, 1984: 340) ${ }^{3}$. Para Sarlo, la literatura de Cortázar radica en las „,consecuencias del pasaje entre espacios que la visión normalizada mantiene escindidos” y Cortázar, „romántico”, intenta tender puentes entre ellos (Sarlo, 2007: 265). Como parece obvio, lo esperanzador y lo temible son dos caras de la nueva realidad que acecha del otro lado.

A su vez, en Stachura las premoniciones de lo trascendente marcan pautas en una vida orientada al desarrollo espiritual. Su narrador tiende a rehuir el discurso intelectual, y su reflexión sirve para analizar sus propias reacciones hacia lo que le ocurre, para, por esa vía, llegar a conocerse y anular el sufrimiento existencial (Brach-Czaina, 1984: 112 y pp.) En su obra es particularmente intensa la impresión de que

${ }^{3}$ Todas las citas proceden de la siguiente edición: Julio Cortázar, Rayuela, Editorial La Oveja Negra, Bogotá 1984. A propósito de esas experiencias, el mismo autor explica, posicionándose en el contexto cultural de la época: “¡No!, no me refiero concretamente a cosas que están un poco demasiado de moda en Occidente, como el Budismo Zen del que ahora se hace un consumo sólo comparable al de la cocacola, pero sí a esos estados - creo que la palabra estados, en este caso, es bastante justa - en los que bruscamente un hombre que ha alcanzado la máxima tensión de su espíritu (...) un punto de vista en el cual el tiempo y el espacio ordinarios se le revelan como meras aceptaciones (en realidad meros instrumentos de trabajo del espíritu) que tal vez una gran ofensiva del hombre podría quebrar si realmente él ha de llegar a ser alguna vez ese nuevo hombre del que tanto se insinúa y tanto se espera en Rayuela". (Margarita García Flores, Entrevista con Julio Cortázar, Revista de la Universidad de México, vol. 21, núm. 7, marzo 1967, pp. 12-13). 
existe un fuerte vínculo entre la literatura y la vida del autor mismo; este último dejaría en su texto el testimonio de la búsqueda de la verdad sobre su propia existencia (íbid.) ${ }^{4}$. Su narrador es hipersensible, en estado de permanente pugna con la civilización materialista y la muerte. Las cuasi religiosas "epifanías de todo resplandor" (término que alude al título de la novela de 1969 [Januszkiewicz, 1994: 106]) surgen de las situaciones cotidianas o de la observación de los milagros diarios (nubes, puesta del sol); ello nos hace pensar, entre otros, en el giro anticivilizatorio de los hippies, que pretendían recibir el aprendizaje de la naturaleza con sus ciclos lentos (Fairfeld cit. por Jawłowska, 1975: 232).

El sol nos entibiaba, y el cielo limpio, despejado tenía precisamente ese color, al que se refería Witek cuando le pregunté:

-¿Cómo vas, Witek?

-Ay, Edmund. Estoy como ese azul."

(Cała jaskrawość, 1974: 54)

Los narradores de ambos autores - como Horacio Oliveira, Michał Kątny, Juan, Edmund Szerucki - transmiten su visión personalísima en unos monólogos heterogéneos, irónicos, llenos de citas de literatura, filosofía y cultura popular, así como de arrebatos líricos. En ambos casos, este discurso conforma una imponente aventura verbal y existencial y produce un vertiginoso efecto de "autenticidad", atribuida a unos personajes atractivos intelectualmente aunque complicados emocionalmente.

El llamamiento a internarse en una dimensión que va más allá de la rutina diaria es un motivo constante en las narrativas en cuestión. En Cortázar, una "empecinada búsqueda ontológica" (expresión del mismo autor ${ }^{5}$ ) hace a los protagonistas asomarse a diversas imago mundis, tales como, la más famosa quizá, del kibbutz del deseo, y otras, como la última casilla de la rayuela llamada cielo, la rosa policromada, la

${ }^{4}$ Henryk Bereza forja a propósito de la obra de Stachura el término de "literatura-vida" (życiopisanie) (Bereza, 1987: 445-465).

5 Expresión de una carta a Roberto Fernández Retamar de 1967 (1993: 145). 
mandala, el yonder (Shaw, 2005: 100). Stachura añade otras imágenes al repertorio, como, por ejemplo, la de una "bola de cristal que se desliza navega rueda por las infinitas rutas celestiales y guarda las respuestas a dos o tres preguntas” („Nocne popołudnie”, en: Się, 1988: 39 ), o la de los "hermosos confines" (cudne manowce) ${ }^{6}$. Estas figuraciones del absoluto son básicamente espaciales y de ahí surge la idea de la frontera: en Cortázar puede tratarse de una puerta entreabierta, una ventana, un muro, incluso del fondo de un bolso de mujer:

Se tiene la impresión de que el cierre defiende el ingreso a una casa zodiacal, que cuando los dedos de esa mujer encuentren la manera de deslizar el fino vástago dorado y que con una media vuelta imperceptible se suelte la traba, una irrupción va a deslumbrar a los parroquianos embebidos en pernod y Vuelta de Francia, o mejor se los va a tragar, un embudo de terciopelo violeta arrancará al mundo de su quicio. (Rayuela, 1984: 359)

... o en última instancia, del ojo del culo (al final de la famosa escena con la clocharde en Rayuela). La misma acción de entrever algo que está más allá (o más acá, según se mire) se observa en Stachura:

[Witek] estaba medio sentado, medio acostado en la paja, con los pies estirados debajo de la manta. Se apoyaba con los codos hincados, echados un poco para atrás. Los ojos los tenía abiertos. Estaba mirando. Mirando hacia donde yo también, a menudo, demasiado a menudo procuraba asomarme. Por encima de esa valla tan alta. Ahora era Witek quien hacia allá estaba mirando. Yo lo miraba a él y era como si me hubiera recostado en la valla y entrecruzado los dedos de ambas manos, para hacerle un escalón. Witek se subió así a mis hombros, se enderezó, yo me enderecé, y ahora él estaba mirando por encima de ese cercado tan alto, alzándose aún más sobre la punta de los dedos. Y cuando empezó a hablar, era como si yol e hubiera preguntado: ¿qué estás mirando?”

(Cała jaskrawość, 1974: 317)

${ }^{6}$ Expresión que ha pasado al acervo del lenguaje de los amantes de su obra.

${ }^{7}$ Esta y las demás traducciones de los fragmentos de la obra de Stachura al español son mías - N.P. 
El " cielo" de la rayuela, el kibbutz, el otro lado, los confines hermosos - estos motivos espaciales son susceptibles de interpretarse en diferentes planos. En el plano sicológico, el contacto con la otra dimensión puede actuar terapéuticamente. Johnny, de El perseguidor, de Cortázar, siente, en los momentos extáticos de su improvisación en el saxo, un alivio parecido al de la vuelta al hogar familiar: "Era la seguridad, sueños, ¿no te parece?, cuando todo está resuelto, Lan y las chicas te esperan con un pavo al horno, en el auto no atrapas ninguna luz roja, todo va dulce como una bola de billar. (,El perseguidor”, de: Las armas secretas, 1999: 58). También el narrador de Stachura siente apaciguado su tormento cotidiano en un estado cercano al nirvana:

Yo soñaba con el absoluto. Olvido ilimitado. Yo soñaba con que me olvidaran todos. Con que me evaporara de la memoria de todas las cabezas hacia el más profundo olvido. Que no guardaran de mí los que me conocen ningún recuerdo, ninguno, nada, la más mínima noticia. Yo soñaba: que la suerte os acompañe, y a mí el silencio. (...) Y deseaba, pasando yo por un pueblo de noche, en un olvido inmenso, no me ladrasen los perros.” („Czysty opis”, en Falując na wietrze, 2001: 217)

Pero al mismo tiempo, para rebajar el impacto de las fantasías paradisíacas, se utiliza el revulsivo de la ironía, a la que son particularmente dados los personajes cortazarianos: „complejo de la Arcadia, retorno al gran útero, back to Adam, le bon sauvage. (y van...). Paraíso perdido, perdido por buscarte, yo, sin luz para siempre." (Rayuela, 1984: 349).

En otras ocasiones, el más allá se carga de valores sociales y políticos. Recordemos que la instauración de "otra realidad" era también uno de los objetivos de los movimientos alternativos, que planeaban transformar sociedades enteras, rechazando las imposiciones del estado corporativo y tecnocrático y sustituyendo la falsa conciencia con una trascendental (véanse los escritos de Charles Reich, Timothy Leary, Raoul Veneigem o Guy Debord, ver Furmanek, 2007, doc. electr.) En Cortázar y Stachura, las opiniones expresadas en el universo ficcional van en una dirección parecida, atacando la sociedad consumista 
y la alienación del trabajo: "la conformidad vacuna, la alegría barata y sucia del trabajo y el sudor de la frente y las vacaciones pagadas" (Rayuela, 1984: 452). Se critica asimismo la rigidez del pensamiento que caracteriza a la mayor parte de la sociedad:

no quieren conocer ese conocimiento, lo olvidan, lo arrojan al olvido, a una vasta sombra profunda. Porque tienen miedo, no tienen coraje, no son capaces de una mirada circular resplandeciente (...) Su cabeza encorsetada en el cuello almidonado de su camisa apenas la pueden mover, únicamente hacia abajo, al hacer la reverencia. Y así les va, cómoda pero unilateralmente. Sólo leen una página del gran libro. Y así les va, comodistas más unilateralistas (...) como de un cadáver despojos ante la puerta roja del sol. (Cała jaskrawość, 1974: 71)

Al mismo tiempo la otra dimensión, se entiende también como el centro de imantación, de las energías humanas más auténticas, las pulsiones sexuales por cuya liberación abogaban Erich Fromm o Herbert Marcuse. El kibbutz del deseo cortazariano es una:

ciudadela sólo alcanzable con armas fabulosas, no con el alma de Occidente, con el espíritu, esas potencias gastadas por su propia mentira (...) esas coartadas del animal hombre metido en un camino irreversible. Kibbutz del deseo, no del alma, no del espíritu. Y aunque deseo fuese también una vaga definición de fuerzas incomprensibles, se lo sentía presente y activo, presente en cada error y también en cada salto adelante, eso era ser hombre, no ya un cuerpo y un alma sino esa totalidad inseparable. (Rayuela, 1984: 196)

Sin embargo, no se trataba solo de criticar la alienación económica e ideológica sino de transformar las relaciones humanas, hacerlas más espontáneas. Aunque en Stachura se vagabundea por un paisaje humilde de la Polonia rural y en Cortázar por las metrópolis (París, Buenos Aires), para ambos automarginarse de la grey burguesa significa romper con la esclavitud del "sistema". En Rayuela la marginación llega a su extremo cuando Oliveira realiza ejercicio que es ascético al revés: se emborracha con la clocharde Emanuelle y, superando el reflejo de 
náusea, copula con ella; en recompensa le llega la iluminación, la premonición del posible ingreso en la trascendencia:

Tal vez el único camino al kibbutz, eso no podía ser el mundo, la gente agarraba el calidoscopio por el mal lado, entonces había que (...) tirarse al suelo como Emmanuèle y desde ahí empezar a mirar desde la montaña de bosta, mirar el mundo a través del ojo del culo, and you'll see patterns pretty as can be, la piedrita tenía que pasar por el ojo del culo, metida a patadas por la punta del zapato, y de la Tierra al Cielo las casillas estarían abiertas. (Rayuela, 1984: 207)

Liberar las pulsiones suponía también la instauración de un anti-orden social basado en la provocación, el azar y la concepción de una realidad subordinada a la imaginación y los instintos (en la senda del dadaísmo y surrealismo; Picón-Garfield 1975: 151-152; Jawłowska 1975: 241-242). Las actitudes provocadoras de los personajes se conectan de igual modo con las primeras vanguardias europeas como con los movimientos nuevos, por ejemplo, los situacionistas europeos de los años 60. En Libro de Manuel, la novela de Cortázar más políticamente marcada, hay un espectáculo que consiste en estar sentados frente a una pared de ladrillos. Este acto, aparentemente intrascendente, adquiere una importancia inesperada, porque los que están mirando la pared en realidad "sospechan lo que puede haber del otro lado" y porque "ese absurdo de ir hacia lo absurdo es exactamente lo que hace caer las murallas de Jericó" (1975: 21). Un acto seudoestético equivale pues a experimentar ,nuevas formas de intervención político-existencial” e imaginar „rumbos novedosos para la lucha revolucionaria" (Peris Blanes, 2014: 34). El otro lado de ese muro de ladrillos insinúa significados políticos, pero se trata del compromiso político en su plano más profundo, el de las transformaciones de la conciencia.

Cabe añadir que, aunque en la obra cortazariana los mensajes políticos se hacen más explícitos en los años 70 (como en la novela antes mencionada), el autor supo evitar el propagandismo. Siempre le ha dado prioridad a lo que él consideraba la única manera honesta, para un escritor, de hacer revolución: "Incapaz de acción política, no renuncio a mi solitaria vocación de cultura, a mi empecinada búsqueda 
ontológica, a los juegos de la imaginación (...)" (“Carta a Roberto Fernández Retamar del 10 de mayo 1967”, cit. por Fernández Retamar, 1993: 145). El compromiso en y para Cortázar consiste en sacudir al lector de su pasividad arrojándolo a la estructura abierta de sus novelas y su fluctuante narración. En cuanto a Stachura, un insólito culto posterior a su muerte (en 1979) le nimbó de un halo contestatario, no obstante los imperativos implícitos en su universo ficcional parecen apelar más a la moral individual que al compromiso socio-político. No se encuentra en sus escritos la menor traza de disidencia (Fedecki, 1990: 270). Si había lucha, era con su propia hipersensibilidad, que le hacía exagerar el sufrimiento causado por la falta de aceptación en su entorno (íbidem: 271).

Al crear situaciones desconcertantes a partir de las rutinas o al fijar la mirada en los objetos cotidianos, las tácticas de los protagonistas conectan con la idea surrealista de fusionar vida, arte y política. Cortázar les hace a sus protagonistas (Rayuela, 62/Modelo para armar, Libro de Manuel) organizar acciones provocativas en restaurantes y otros espacios públicos. O inventa a una serie de personajes fantásticos en Historias de cronopios y famas (1962). Los famosos cronopios son definidos como "objetos verdes y húmedos" y en una curiosa coincidencia, Timothy Leary hace una descripción parecida del integrante típico del underground de los años 60. éste sería ,libre, extático, sensual y húmedo" (Leary, 1998: 140). El cronopio se fija en las flores, recoge hilos de colores y otras nimiedades, entregándose a actividades frívolas: „Cuando un cronopio canta, las esperanzas y los famas acuden a escucharlo aunque no comprenden mucho su arrebato"s ("El canto del cronopio", 1995: 73). Este tipo de personaje encarna el lado hedonista y lúdico de la narrativa de Cortázar, siendo un contrapeso para su marcado intelectualismo.

Adoptando otra perspectiva, desde los márgenes, o simplemente renunciando a las prisas y contemplando los objetos de uso diario, se hace posible entender, entre otros, cómo nos esclavizan los

${ }^{8}$ La traductora polaca Zofia Chądzyńska traduce significativamente "arrebato" por "ekstaza" (éxtasis). 
mecanismos sociales y económicos; por ende, es el primer paso hacia la liberación. El narrador de Stachura opta por una actitud parecida, al abandonar su escritura a las peripecias de la vida errante y asumiendo el papel del cantor de las cosas sencillas (uno de sus relatos está basado en los objetos que lleva en su mochila ${ }^{9}$ ). Es por esa atención respetuosa hacia la inmediata realidad que la crítica ha comentado repetidas veces el espíritu franciscano de su obra (ver Pachocki, 2007: 20 y pp.) De la humilde contemplación nacen estados quietistas y místicos:

Para la eternidad. Así nos fuimos a sentar. (...) viviendo en medio de esa inspiración, incesante como los latidos del corazón, la circulación de la sangre o la boca que inspira aire, una actividad del todo común se teñía de colores inusuales, dejando así de ser común, cobrando tanto peso, brillo, esplendor, una tan espantosa alegría y tristeza, que yo me entregaba de lleno a esa actividad. De manera absoluta, como si fuera para la eternidad. Para siempre. (Cała jaskrawość, 1974: 131 - trad. mía, N.P.)

Para capturar los fulgores que reverberan en lo cotidiano y las señales del más allá (o más acá) liberador, ambos autores optan por un discurso narrativo digresivo, fragmentado, dado a la crítica, autocrítica e ironía. Los estilos de ambos refunden con gracia los registros cultos y populares, sin despreciar la creatividad verbal y la broma. Esta tendencia aligera el tono a menudo sombrío, sobre todo en la prosa de Stachura, dolorida y emotiva.

¿Qué significados adquiere hoy el impulso hacia los espacios trascendentes tan notorio en la obra de estos autores? A finales a fines / a finales: to samo de los 60, al comparar las aspiraciones de sus personajes en Rayuela con la actitud contestataria de la juventud americana y europea de sus tiempos, Cortázar decía: ,yo tengo ahora, a posteriori, la impresión de que lo que hice con ese libro fue simplemente responder a ciertas cosas que estaban en el aire" (cit. por García Flores, 1967: 12). Rayuela representaba, según su autor, una „especie de crítica metafísica total" que planteaba en términos de novela los grandes interrogantes, las grandes preguntas de los filósofos (íbid. 1967: 11).

\footnotetext{
${ }^{9}$ „Słodycz i jad” del volumen Się.
} 
A través de ellas, la generación de Cortázar y Stachura expresaba la urgencia de replantear las bases de la sociedad, rechazando un sistema basado en la enajenación del hombre por la tecnología y el consumo.

Pero es cierto (y natural) que el potencial subversivo presente en la obra del argentino probablemente ya no encuentre conexión con las transformaciones actuales de la sociedad occidental. Por lo cual no se sugiere de ningún modo que el valor literario no haya sobrevivido al momento y a la circunstancia de su gestación. Aunque cierto "cortaziarianismo" facilón pueda hoy deplorarse (“... esa onda sesentista tan bien sintonizada con la moda hippie, las polleras hindúes ... la ginebra, el rock, el Woodstock, el anticonvencionalismo, la izquierda florida", Sarlo, 2007: 264), Cortázar en sí mismo sigue siendo en la actualidad un clásico incuestionable de la narrativa en lengua española y de la literatura mundial contemporánea.

La situación de Stachura es diferente: su recepción se limitó al espacio cultural polaco. Su mito adquirió unas dimensiones desproporcionadas tras su suicidio en 1979 y se fue perpetuando en festivales de canciones poéticas y reuniones sectarias, donde al autor se le rendía un culto cuasi religioso. En los 80 el autor fue una referencia obligatoria para la juventud de guitarra y mochila, que desafiaba el comunismo europeo centrooriental en declive. Se veía en él un gurú espiritual, sobre todo porque en sus escritos finales se evidencia un giro hacia la disolución del yo cercano al budismo y otras doctrinas orientales. Un crítico afirmaba al respecto que "el místico infantiloide y poco original filósofo Stachura, ha eclipsado totalmente al muy original poeta Stachura" (Fedecki, 1990: 270). Dicho sea de paso, es precisamente y sobre todo la poesía amorosa de Stachura la que le asegura aún hoy la entrega de un público fiel ${ }^{10}$.

Reiterando la pregunta: ¿es aún estimulante hoy el modelo del narrador rebelde y a la vez deseoso de atravesar la superficie de una

${ }^{10}$ Es justo añadir que desde los años 80 . del s. XX se han publicado nuevas investigaciones, donde tanto la personalidad como el arte literario de Stachura se han enjuiciado con buen criterio. Véase, por ejemplo, Dariusz Pachocki (2007) o Marian Buchowski (2017). 
existencia engañosa y opresora? ¿Un protagonista que quiera „navegar por el arco iris hacia su otro lado desconocido"? (como cantaba Mira Kubasińska del grupo "Breakout", que era la respuesta polaca al rock folclórico y sicodélico) ${ }^{11}$.

Las búsquedas de los protagonistas actuales parecen no apuntar ya hacia las dimensiones metafísicas. En cambio, son más frecuentes, aunque desde luego es una generalización, las investigaciones seudopolicíacas, en las que el crimen ocupa el lugar de la gran metáfora cognoscitiva y existencial. En el ámbito de la lengua española, la literatura de Roberto Bolaño (1953-2003) es un ejemplo magistral de esta tendencia. A caballo del siglo XX y XXI, Bolaño renovó a su modo to jest to samo el motivo de la persecución tenaz de un misterio, creando un suspense siempre postergado. Pero en vez de liberador, ese misterio inefable se percibe como criminal y maligno.

En los espacios inauditos del absoluto convocados en la prosa de Cortázar y Stachura - kibbutz o los „,confines” cubiertos de brezalesla realidad defectuosa se transformaba y el reino del deseo parecía instaurarse momentáneamente. Eran cifras de un más allá anhelado, que subyugaban con una fuerza particular en los tiempos del flower power.

\section{Obras de Julio Cortázar citadas}

Rayuela (1984) [1963], ed. Oveja Negra, Bogotá.

Libro de Manuel (1995) [1973], Alfaguara, Buenos Aires.

"El perseguidor" (1999) [1959], En: Las armas secretas y otros relatos, El Mundo Unidad Editorial, Madrid.

"El canto de los cronopios" (1995) [1962], En: Historias de cronopios y de famas, Alfaguara, Buenos Aires.

\section{Obras de Edward Stachura citadas:}

Cała jaskrawość [Todo resplandor] (1974), Ludowa Spółdzielnia Wydawnicza, Warszawa.

${ }^{11}$ Cita de la canción "Na drugim brzegu tęczy" [Del otro lado del arcoiris], 1969, letra: Franciszek Walicki, música: Tadeusz Nalepa. 
Relatos „Nocne popołudnie” [Un mediodía de noche] y „Wesele” [Boda], en: Się [Uno, 1977] (1988), Ludowa Spółdzielnia Wydawnicza, Warszawa.

Relato „Czysty opis” [Descripción pura, 1962-66] y “Falując na wietrze”, del volumen Falujac na wietrze [Meciéndose en el viento], en: Opowiadania (2001), Wydawnictwo C\&J, Toruń.

\section{Bibliografía}

BEREZA, H. (1987), Życiopisanie, postfacio a: Edward Stachura, Poezja i proza, t. 5: Fabula rasa. $Z$ wypowiedzi rozproszonych, Rutkowski, K. (ed.), Czytelnik, Warszawa.

BUCHOWSKI, M. (2017), Buty Ikara. Biografia Edwarda Stachury, Iskry, Warszawa.

BRACH-CZAINA, J. (1984), Etos nowej sztuki, PWN, Warszawa.

ELBANOWSKI, A. (1985), "Obrzędy - Gry - Przejścia. Opowiadania Julio Cortazara", Literatura na świecie, 2, pp. 107-126.

FEDECKI, Z. (1990), “Moda na Stachurę”, en: Kolbus, E., (ed.), Kaskaderzy literatury, Wydawnictwo Łódzkie, Łódź, pp. 130-135.

FERNÁNDEZ RETAMAR, R., (1993), Fervor de la Argentina. Antología personal, colección "Los nuestros", 9, Ediciones de Sol, Buenos Aires.

FURMANEK, Ł. (2007), "Rewolucyjne wizje teoretyków kontrkultury", Kultura i Historia, 12, [on-line] http://www.kulturaihistoria.umcs.lublin. $\mathrm{pl} /$ archives/478, 8.08.2016.

GARCÍA FLORES, M. (1967), "Entrevista con Julio Cortázar”, Revista de la Universidad de México, 21, 7, pp. 10-13.

GASZYŃSKA-MAGIERA, M. (2011), Recepcja przekładów literatury iberoamerykańskiej w Polsce w latach 1945-2005 z perspektywy komunikacji międzykulturowej, Wydawnictwo Uniwersytetu Jagiellońskiego, Kraków.

JANUSZKIEWICZ, M. (1994), “Od egzystencjalizmu do mistyki. O prozie Edwarda Stachury”, Pamiętnik Literacki, 4, pp. 96-115.

JAWŁOWSKA, A. (1975), Drogi kontrkultury, Państwowy Instytut Wydawniczy, Warszawa.

LEARY, T. (1998), Polityka ekstazy, trad. D. Misiuna, R. Palusinski, Wydawnictwo EJB, Kraków. 
PACHOCKI, D. (2007), Stachura totalny, Wydawnictwo Katolickiego Uniwersytetu Lubelskiego, Lublin.

PERIS BLANES, J. (2005), “«Libro de Manuel» de Julio Cortázar, entre la revolución política y la vanguardia estética”, Cuadernos de investigación filológica, 31-32, pp. 143-161.

PICÓN GARFIELD, E. (1971), "Lo maravilloso en la realidad cotidiana”, en: Pedro Lastra (ed.), Julio Cortázar, „El escritor y la critica”, Taurus, Madrid.

SANKOWSKI, R. (2012) "Płyta Babu Króla z piosenkami Stachury. Bitnik Sted", Gazeta Wyborcza, suplemento "Kultura", 27 de junio de 2012.

SARLO, B. (2007), Escritos sobre literature argentina, Saítta, S. (ed.), Siglo XXI, Buenos Aires.

SHAW, D.L. (1999), Nueva narrativa hispanoamericana. Boom. Posboom. Posmodernismo, Cátedra, Madrid. 